\title{
Impact of COVID-19 First Official Vaccine Approval on Precious Metals: A Behavioral Finance Approach
} (Research Article)

Covid 19 İlk Resmi Aşı Onayının Kıymetli Madenler Üzerindeki Etkisi: Davranışsal Finans Yaklaşımı

Doi: 10.29023/alanyaakademik.1030370

\section{Çağrı HAMURCU}

Dr. Öğretim Üyesi, Aksaray Üniversitesi, Ortaköy Meslek Yüksekokulu, cagri.hamurcu@gmail.com

Orcid No:0000-0002-3248-6733

How to cite this article: Hamurcu, Ç. (2022). "Impact of COVID-19 First Official Vaccine Approval on Precious Metals: A Behavioral Finance Approach”, Alanya Akademik Bakış, 6(1), Sayfa No 1799-1807.

Keywords:

Behavioral finance, gold, silver, platinum, palladium, EGARCH, COVID-19, vaccine

Received: 30.11 .2021 Accepted: 20.01.2022

\begin{abstract}
This research aims to reveal the effect of first official COVID-19 vaccine approval on precious metal prices in terms of return and volatility. Within the context of precious metal, gold, silver, platinum, and palladium are selected as dependent and US dollar index as independent variables. In order to measure the difference in the returns and volatilities before and after the first official approval of the COVID-19 vaccine, a dummy variable is defined. Analysis studies have been carried out with EGARCH models. According to the results, it is determined that the first official COVID-19 vaccine approval had negatively affected the level of volatility for gold and silver prices. The approval does not affect the volatility of platinum and palladium. Besides, a negative relationship is found between both all precious metals and the US dollar index in terms of returns. It is assumed that the results could be interpreted as investors acted by the risk aversion bias before the first official approval of the COVID-19 vaccine, and the approval created an effect of reducing uncertainty in the financial markets.
\end{abstract}

\section{INTRODUCTION}

The knowledge acquired by investors during the decision-making process, the perception created by this information on the investor, and the investor behavior shaped by the investor perception affect the financial market dynamics.

Many investors can review their opinions on new information and news and investment instruments and revise them when necessary. As a result of the renewal of the idea about the investment tool, the investor may buy, sell, or not show any action. With the effect of herd behavior, the effects of these trends could magnify and have significant effects on the markets.

Rapid developments in the technology and communication sectors have made the speed of accessing information very easy and increased the reaction to the information accessed. This situation has enabled the financial markets to provide global liquidity to investors, and the process of reflecting the effect of information on prices has accelerated. One possible result of the process is that it makes possible the rapid change in prices and an increase in volatility. 
Volatility appears to investors as an important factor in financial investments and is known to be quite a determinant in investment decisions (Schwert, 1990).

In times of crisis and uncertainty, market dynamics change with the effects of behavioral trends. Pandemic periods are also among the periods in which the effects of uncertainty are seen at a high rate. In this context, studies are carried out to reveal the effects of Covid-19, which is described as a pandemic, on financial markets. Variations in the return and volatility of precious metals, which are among the important instruments of the markets, have also been a matter of curiosity during the COVID-19 pandemic period.

This study differs in that it considers the pre-and post-process of the first official approval of COVID-19 vaccines by the authorities as a research subject and examines this with a model that includes the variables of gold, silver, platinum, palladium, and the US dollar index. This research aims to reveal the effect of first official COVID-19 vaccine approval on precious metal prices in terms of return and volatility.

\section{LITERATURE REVIEW}

Studies that examine the factors affecting the returns and volatility of precious metals and the relationships between these factors and especially the movements of these variables in periods of crisis and uncertainty and the findings of these studies are given below.

The long-term association between gold and silver values for the periods, 1972: 12-1990: 6, 1981: 04-1990: 06, and 1990: 07-1994: 6, was explored by Escribano \& Granger (1998). In this study, the returns of gold and silver were analyzed over the long-term process and it has been concluded that there is a simultaneous connection between the return rates of both precious metals. Also, the interpretation was shared that after 1990, the interdependent relationship of the markets for both metals decreased and almost separated.

In the study of Capie et al. (2005), in which the degree of gold serves as an instrument of hedging against exchange rate risk was evaluated using weekly data, a negative gold-pounddollar-yen-dollar exchange-rate relationship, which changes strength over time, was found. In this study, the finding was shared that gold functions as a hedge against adjustments in the exchange value of the dollar, and this is due to some degree of unpredictable attitudes and incidents in politics.

The volatility of returns on financial assets varies over time. The ability to predict the future volatility level of financial assets varies depending on the characteristics of the model established, the accuracy of the parameters, and the level of volatility, and it becomes difficult from time to time (Brandt \& Jones, 2006).

Another research analyzed the typical changes between the spot prices of precious metals (gold, silver, platinum, and palladium), the price of oil, and the US dollar/euro exchange rate, strong short-term feedback was found as well as proof of poor interaction between variables in longterm balance (Sari et al., 2010). In addition, this research contains the observations that major transient responses to shocks at some of the other metal prices and exchange rates are given by the precious metal spot markets. In the study in which gold, silver, platinum, and palladium price volatilities were modeled and the macroeconomic determinants of these volatilities were investigated, it was concluded that monetary factors explained the volatility of gold, but this situation did not extend to silver (Batten et al., 2010). There is also insufficient evidence that 
the volatility procedures of the precious metal price series are collectively influenced by macroeconomic conditions.

In Joy's study (2011), gold, US dollar, and related exchange risk variables were investigated. According to the results of the study, it was stated that, over a period of 23 years, gold behaved as a financial asset that provides protection against the US dollar and the associated exchange rate risk and acts as a shelter.

Baur's study (2012), which measures the response of gold's volatility to positive and negative shocks, emphasizes that there is an inverse asymmetric reaction between variables, that positive shocks improve volatility more than adverse shocks, and this effect is related to the property of gold being a safe haven (Baur, 2012). In this study, it is also stated that the favorable shifts in gold prices are perceived by investors as a warning signal of future uncertainties and negative returns of other financial assets. It is shared as another finding obtained in the study that this effect mechanism described causes uncertainty in the gold market and thus higher volatility.

In the study, which examines the diversity over time in the safe harbor characteristics of gold, silver, platinum, and palladium, the finding that silver, platinum, and palladium showed the characteristics of safe shelters in periods when gold did not show the feature of safe shelter (Lucey \& Li, 2015).

In a study conducted by Otero \& Reboredo (2018), in various periods of volatility (pre-crisis, crisis, and post-crisis) between January 2005 and June 2015, the relative risk-adjusted returns and downside risk output of precious metal mutual funds were analyzed. In the light of the results obtained, it has been determined that the move from low uncertainties to high uncertainties has a positive impact on risk-adjusted returns of precious metal mutual funds, which loses its effect when uncertainty decreases. It is expressed that precious metal investment fund investors could benefit from their investment strategies thanks to this dynamic that has been revealed regarding the movements of precious metals in periods of uncertainty.

Within the scope of behavioral finance studies that show that investor sentiment influences investment choices, a study was conducted to examine the effect of the combination of geographic proximity to the source region of the epidemic and heavy media coverage on stock prices in the US (Ichev \& Marinč, 2018). In this study, it was concluded that information about the Ebola epidemic events has an increasing impact on financial markets and companies in relation to geographic proximity. In addition, it is another result expressed in the study that the overemphasized epidemic event caused an increase in investor risk perception and increased volatility in the markets by creating behavioral finance biases.

In the study, which examines the effects of many factors such as the dollar index, exchange rate, oil, and stock market index on the global gold price, it is shared that many factors affect the gold price negatively (Qian et al., 2019).

It was determined in the study (Mensi et al., 2020) that The impact on gold and oil prices of COVID-19, which were less efficient in the prices for gold and oil, especially during the epidemic period, was examined according to ascending and descending patterns. The gold market was found to be less effective during declining cycles prior to the pandemic, while oil is found to be less efficient in upward trends.

Qin et al. (2020) researched the necessity of the storage of gold in chaotic periods from a geopolitical risk perspective. It was stated that because of its rising price overtimes, gold should 
be set aside when geopolitical risks are high, but the negative effect does not confirm this view. It is also suggested in this study that investors and governments can take advantage of the value of gold in chaotic times to prevent losses and optimize investments.

Gharib et al. (2020) studied examined the effect of excessive pricing on crude oil and gold markets, which can be described as the bubble created by the COVID-19 outbreak, it was found that this effect was bilateral. The risk aversion environment that occurs during periods of excessive uncertainty in financial markets is another dynamic expressed in this study, where investors turn to financial assets that are considered safer such as gold.

Examining the return-volatility relationship in some commodity prices, including gold, Chen $\& \mathrm{Mu}$ (2020) concluded that most of the daily spot prices have reverse leverage. In other words, it is stated that the volatility that resulted after the positive market shocks was considered to be larger.

Calvimontes et al. (2020) analyzed the changes in gold mining prices in the context of the COVID-19 outbreak, it is stated that the effect on gold mining of the COVID-19 pandemic is both widely varying and uncertain In addition, this study reveals that this situation has an important effect on the gold price as well as the development of the sector.

In the study, where the accuracy of the opinion that there is a negative relationship between gold and the dollar was investigated and the situations where this relationship was violated, evidence was obtained that there was a short-term positive relationship between gold and the dollar in times of extraordinary market conditions (He et al., 2020). This result is expressed as an indication that the property of gold, expressed as having risk security, is influenced by the phase of the gold-dollar threshold.

\section{MATERIAL AND METHODS}

In this study, gold, silver, platinum, and palladium are selected as dependent variables of the study. A dummy variable is defined to measure the difference in the returns and volatilities of gold, silver, platinum, and palladium before and after the first official approval of the COVID19 vaccine. Analysis studies have been carried out with EGARCH models. The dummy variable and the US dollar index are added to these models as independent variables.

The EGARCH model was defined as an exponential GARCH (Generalized Autoregressive Conditional Variable Variance) method in order to determine the asymmetric effects of positive and negative shocks on volatility and to avoid the constraints in other volatility models (Nelson, 1991). EGARCH model emerges as a model that defines the dynamics of logarithmic volatility.

The daily USD prices of Gold, Silver, Platinum, Palladium used in the study are taken from the London Bullion Market Association (LBMA) web page (http://www.lbma.org.uk/preciousmetal-prices\#/) and US Dollar Index (DXY) data is obtained from www.indexing.com financial data portal.

The daily values of the variables in our study are included in the analysis between the date of 11.03.2020 when the spread of COVID-19 is defined as a pandemic and 30.12.2020. The values for the dummy variable are set as " 0 " for before the UK approval date of the COVID 19 vaccine (02.12.2020), and " 1 ” for after. 


\section{RESULTS}

The outcomes achieved in the study are presented in this section. Descriptive statistics for the variables of gold, silver, platinum, and palladium prices and the American Dollar Index are given in Table 1. Positive standard deviations obtained for daily returns of all variables given in Table 1 indicate that there is a variation from the mean values and a high level of variability in price changes. It is understood that precious metals with a skewness value less than zero are skewed to the left and the American Dollar Index variable with a skewness value greater than zero is skewed to the right.

Table 1: Descriptive Statistics for Variables

\begin{tabular}{|l|c|c|c|c|c|}
\hline & Gold & Silver & Platinum & Palladium & DXY \\
\hline Mean & 1812.974 & 21149.93 & 864.7415 & 2153.532 & 95.35151 \\
\hline Median & 1842.000 & 23160.00 & 868.0000 & 2213.000 & 93.96000 \\
\hline Maximum & 2067.150 & 28885.00 & 1068.000 & 2483.000 & 102.9900 \\
\hline Minimum & 1474.250 & 12005.00 & 593.0000 & 1583.000 & 89.68000 \\
\hline Standard Deviation & 120.4009 & 4647.781 & 92.36817 & 203.4479 & 3.261750 \\
\hline Skewness & -0.521074 & -0.227971 & -0.192070 & -0.584058 & 0.350131 \\
\hline Kurtosis & 2.757576 & 1.628082 & 2.977239 & 2.403797 & 1.968011 \\
\hline Jarque-Bera & 9.778869 & 17.85243 & 1.264858 & 14.69125 & 13.28545 \\
\hline Probability & 0.007526 & 0.000133 & 0.531300 & 0.000645 & 0.001303 \\
\hline Observations & 205 & 205 & 205 & 205 & 205 \\
\hline
\end{tabular}

In addition, when the distributions are examined in terms of kurtosis, it is revealed that all variables have a flat appearance. In terms of Jarque-Bera and probability values, it is understood that all variables except Platinum do not have a normal distribution.

After this stage, the analysis studies were continued by taking the first differences in the logarithms of all variables. Firstly, unit root tests were conducted to understand whether the variables are stationary or not. Unit root test results are included in Table-2. When the table is examined, it is seen that both variables have every stationary structure at the basic level $(\mathrm{p}<0.05)$.

Table 2. Unit Root Tests for Variables

\begin{tabular}{|c|c|c|c|c|c|c|}
\hline \multirow[b]{3}{*}{ Gold Ons Return USD } & \multicolumn{6}{|c|}{ Models } \\
\hline & \multicolumn{2}{|c|}{$\begin{array}{c}\text { none } \\
\text { exogenous variables }\end{array}$} & \multicolumn{2}{|c|}{$\begin{array}{c}\text { constant } \\
\text { exogenous variables }\end{array}$} & \multicolumn{2}{|c|}{$\begin{array}{l}\text { constant\&lineer trend } \\
\text { exogenous variables }\end{array}$} \\
\hline & t-Statistic & $\mathrm{p}$ & t-Statistic & $\mathrm{p}$ & t-Statistic & $\mathrm{p}$ \\
\hline Augmented Dickey-Fuller & -14.83354 & $0.0000 * * *$ & -14.83317 & $0.0000 * * *$ & -14.81092 & $0.0000 * * *$ \\
\hline $\begin{array}{l}\text { Test critical values } 1 \% \\
\text { level }\end{array}$ & -2.576403 & & -3.462574 & & -4.003902 & \\
\hline $5 \%$ level & -1.942399 & & -2.875608 & & -3.432115 & \\
\hline $10 \%$ level & -1.615659 & & -2.574346 & & -3.139793 & \\
\hline Silver Ons Return USD & t-Statistic & $\mathrm{p}$ & t-Statistic & $\mathrm{p}$ & t-Statistic & $\mathrm{p}$ \\
\hline Augmented Dickey-Fuller & -12.36702 & $0.0000 * * *$ & -12.39471 & $0.0000 * * *$ & -12.36623 & $0.0000 * * *$ \\
\hline $\begin{array}{l}\text { Test critical values } 1 \% \\
\text { level }\end{array}$ & -2.576403 & & -3.462574 & & -4.003902 & \\
\hline $5 \%$ level & -1.942399 & & -2.875608 & & -3.432115 & \\
\hline
\end{tabular}


HAMURCU

\begin{tabular}{|c|c|c|c|c|c|c|}
\hline $10 \%$ level & -1.615659 & & -2.574346 & & -3.139793 & \\
\hline Platinum Ons Return USD & t-Statistic & $\mathrm{p}$ & t-Statistic & $\mathrm{p}$ & t-Statistic & $\mathrm{p}$ \\
\hline Augmented Dickey-Fuller & -12.86261 & $0.0000 * * *$ & -12.84746 & $0.0000 * * *$ & -12.89277 & $0.0000 * * *$ \\
\hline $\begin{array}{l}\text { Test critical values } 1 \% \\
\text { level }\end{array}$ & -2.576403 & & -3.462574 & & -4.003902 & \\
\hline $5 \%$ level & -1.942399 & & -2.875608 & & -3.432115 & \\
\hline $10 \%$ level & -1.615659 & & -2.574346 & & -3.139793 & \\
\hline Palladium Ons Return USD & t-Statistic & $\mathrm{p}$ & t-Statistic & $\mathrm{p}$ & t-Statistic & $\mathrm{p}$ \\
\hline Augmented Dickey-Fuller & -9.328253 & $0.0000 * * *$ & -9.304878 & $0.0000 * * *$ & -9.293911 & $0.0000^{* * * *}$ \\
\hline $\begin{array}{l}\text { Test critical values } 1 \% \\
\text { level }\end{array}$ & -2.576403 & & -3.462574 & & -4.003902 & \\
\hline $5 \%$ level & -1.942399 & & -2.875608 & & -3.432115 & \\
\hline $10 \%$ level & -1.615659 & & -2.574346 & & -3.139793 & \\
\hline DXY Return & t-Statistic & $\mathrm{p}$ & t-Statistic & $\mathrm{p}$ & $\mathrm{t}$-Statistic & $\mathrm{p}$ \\
\hline Augmented Dickey-Fuller & -11.56658 & $0.0000^{* * * *}$ & -11.59987 & $0.0000^{* * * *}$ & -11.65152 & $0.0000 * * *$ \\
\hline $\begin{array}{l}\text { Test critical values } 1 \% \\
\text { level }\end{array}$ & -2.576403 & & -3.462574 & & -4.003902 & \\
\hline $5 \%$ level & -1.942399 & & -2.875608 & & -3.432115 & \\
\hline $10 \%$ level & -1.615659 & & -2.574346 & & -3.139793 & \\
\hline
\end{tabular}

note: $\mathrm{p}=$ probability. $* * *$ significant at 0.01 level.

In order to examine the relationship between precious metals, COVID-19 vaccine studies, and the US Dollar index in terms of return and volatility, the EGARCH models are established among variables. In these models, logarithmic price returns of precious metals are dependent, while COVID-19 vaccine studies and logarithmic returns of the US Dollar index are determined as independent variables. In order to model the difference in the returns of precious metal prices before and after the date when a COVID-19 vaccine was approved for use by the UK for the first time, a dummy variable called COVID-19 Vaccine approvement is defined and added to the models. The results of the EGARCH models established for each precious metal in the study are shown in Table-3.

Table 3. EGARCH Model Coefficients and Heteroskedasticity Test for the Precious Metal Price Return

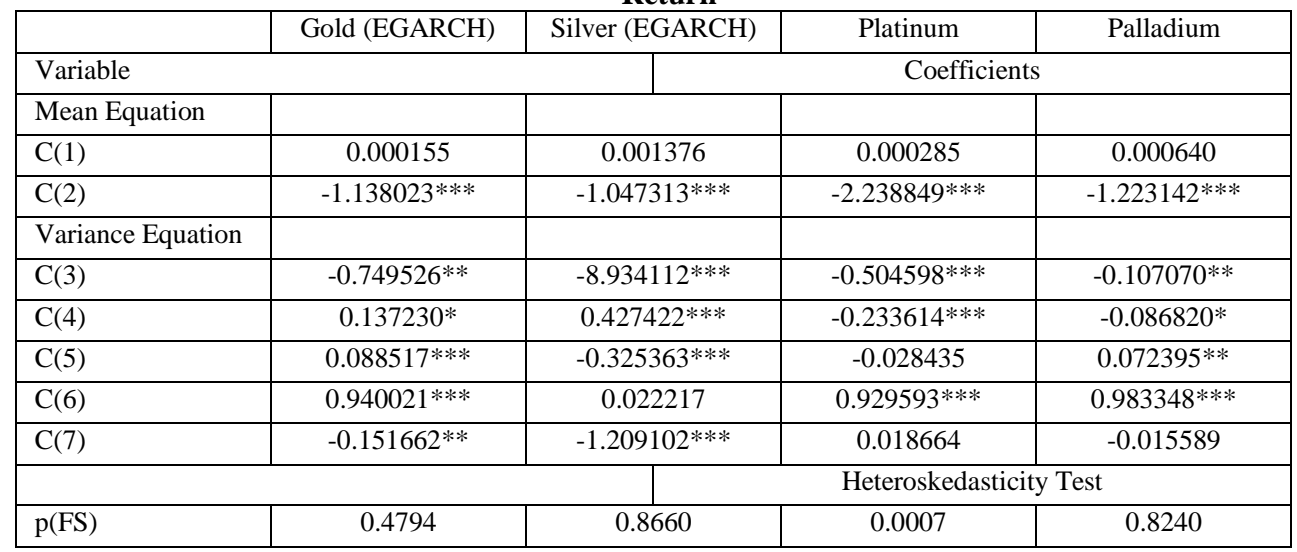


note: $\mathrm{p}(\mathrm{FS})=\operatorname{Prob}(\mathrm{F}-\mathrm{Statistic})$ of Heteroskedasticity test. $* * *$ significant at 0.01 level. $* *$ significant at 0.05 level. * significant at 0.1 level.

The mean and variance equations obtained as a result of the established EGARCH models are given in equations (1) and (2).

Mean Equation $=\mathrm{C} 1+\mathrm{C}(2) *(\mathrm{US}$ Dollar index $)$

Variance Equation

$\log \left(\sigma_{t}^{2}\right)=\mathrm{C}(3)+\mathrm{C}(4)\left|\varepsilon_{t-1} / \sigma_{t-1}\right|+\mathrm{C}(5)\left(\varepsilon_{t-1} / \sigma_{t-1}\right)+\mathrm{C}(6) \log \left(\sigma_{t-1}^{2}\right)+\mathrm{C}(7) *(\mathrm{COVID}-19$

Vaccine Approval)

In this equation, $\sigma_{t}^{2}$ is variance of precious metals.

Considering the mean equation, the fact that the parameter $\mathrm{C}(2)$ is significant for all precious metals. These coefficients are negative for all precious metals.

The fact that the $\mathrm{C}(5)$ parameter is statistically significant indicates the asymmetry in the volatility structure. When the variance equation estimation results given in Table 3 are examined, it is seen that the coefficient of the $\mathrm{C}(5)$ parameter, which shows the effect of asymmetry, is significant for gold, silver, and palladium, but not for platinum. C(5) coefficient is positive for gold and negative for silver and palladium.

C (6) parameters in Table 3 express the permanence of the shock. The coefficients of this parameter are significant for gold, platinum, and palladium.

The statistically significant coefficients of the dummy variable $C(7)$ are negative and statistically significant for gold and silver and insignificant for platinum and palladium.

Since the Heteroskedasticity Test results in Table 3 for platinum are $p(F S)<0.05$, the findings of platinum in the EGARCH model are not significant. On the other hand, since the results of this test for gold, silver and palladium are $\mathrm{p}>0.05$, the findings obtained in the egarch model are significant.

\section{DISCUSSION AND CONCLUSION}

In this section, the results obtained will be interpreted and discussed and suggestions for further studies will be presented.

It is found that there is a downward link between the prices of precious metals and the earnings of the US Dollar Index. In other words, precious metal returns decline as the US dollar index rises, and as the US dollar index declines, precious metal returns rise. This result is compatible with the studies of Capie et al. (2005), Joy (2011), Qian et al. (2019), and He et al. (2020).

On the one hand, positive shocks improve gold price volatility rather than negative shocks, on the other hand, negative shocks increase the volatility in silver and palladium prices more than positive shocks. While extremely positive news is included in the definition of positive shock, on the contrary, news with an extremely negative quality is expressed as a negative shock. In Baur's study (2012), it is found that positive shocks have a greater impact on volatility than adverse shocks. Qin et al. (2020) stated that gold should be stored because of its rising price in times where uncertainties are high, but this opinion is not supported by the negative effects. Chen \& Mu (2020) expressed that it is stated that volatility in some commodity prices, including gold is determined higher after positive price shocks. It was concluded in the study 
of Batten et al. (2010) that although monetary factors mainly describe the volatility of gold, this relationship may not extend to silver and no proof exists that macroeconomic factors affect the volatility dynamics of the price sequence for precious metals.

Another result that the obtained findings indicate to us is that the permanence of the analyzed shock has been found to exist on gold, platinum, and palladium. In the study of Sari et al. (2010), it is stated that significant temporary responses to shocks in some of the other metal prices and exchange rates occur in the precious metal spot markets.

The asymmetric EGARCH $(1,1)$ models, which have been proven for gold and silver as a result of the findings, show that the first official COVID-19 vaccine approval negatively affected the volatility in gold and silver prices during the study period. This relation could be interpreted that investors acted under the risk aversion bias before the approval of the COVID-19 vaccine, and the approval created an effect of reducing uncertainty in the markets. On the other hand, the findings show that the approval of the COVID19 vaccine does not affect platinum and palladium volatility. Otero \& Reboredo (2018) obtained that it has been determined that the move from low unpredictability to high unpredictability has a positive influence on the riskadjusted returns of the mutual funds of precious metals, which, as uncertainty decreases, loses its influence. In the study of Ichev \& Marinč (2018), by developing behavioral finance perceptions, an overemphasized epidemic occurrence triggered a rise in investor risk awareness, elevated uncertainty, and volatility in the markets. Gharib et al. (2020) revealed that the risk aversion environment that exists during times of extreme volatility in financial markets is another dynamic where investors turn to financial assets that are perceived to be safer, such as gold.

The limited working period is among the limitations of this study. For this reason, it is thought that these findings should be expanded to include longer periods to prove their validity. To examine the market dynamics in a wider scope, it may be considered to include other assets and their indicators in the study.

\section{REFERENCES}

BATTEN, J. A., CINER, C., \& LUCEY, B. M. (2010). The macroeconomic determinants of volatility in precious metals markets. Resources Policy, 35(2), 65-71. https://doi.org/10.1016/j.resourpol.2009.12.002

BAUR, D. G. (2012). Asymmetric Volatility in the Gold Market. The Journal of Alternative Investments, 120223000721008. https://doi.org/10.3905/jai.2012.2012.1.016

BRANDT, M. W., \& JONES, C. S. (2006). Volatility forecasting with range-based EGARCH models. Journal of Business and Economic Statistics, 24(4), 470-486. https://doi.org/10.1198/073500106000000206

CAlvimontes, J., MASSARO, L., ARAuJO, C. H. X., MORAES, R. R., MELlO, J., FERREIRA, L. C., \& DE THEIJE, M. (2020). Small-scale gold mining and the COVID19 pandemic: Conflict and cooperation in the Brazilian Amazon. Extractive Industries and Society, May, 1-4. https://doi.org/10.1016/j.exis.2020.08.013

CAPIE, F., MILLS, T. C., \& WOOD, G. (2005). Gold as a hedge against the dollar. Journal of International Financial Markets, Institutions and Money, 15(4), 343-352. https://doi.org/10.1016/j.intfin.2004.07.002 
ESCRIBANO, A., \& GRANGER, C. W. J. (1998). Investigating the relationship between gold and silver prices. Journal of Forecasting, 17(2), 81-107. https://doi.org/10.1002/(SICI)1099-131X(199803)17:2<81::AID-FOR680>3.0.CO;2-B

GHARIB, C., MEFTEH-WALI, S., \& JABEUR, S. B. (2020). The bubble contagion effect of COVID-19 outbreak: Evidence from crude oil and gold markets. Finance Research Letters, July 2020, 101703. https://doi.org/10.1016/j.frl.2020.101703

HE, Q., GUO, Y., \& YU, J. (2020). Nonlinear dynamics of gold and the dollar. North American Journal of Economics and Finance, 52(January), 101160. https://doi.org/10.1016/j.najef.2020.101160

ICHEV, R., \& MARINČ, M. (2018). Stock prices and geographic proximity of information: Evidence from the Ebola outbreak. International Review of Financial Analysis, 56, 153166. https://doi.org/10.1016/j.irfa.2017.12.004

JOY, M. (2011). Gold and the US dollar: Hedge or haven? Finance Research Letters, 8(3), 120-131. https://doi.org/10.1016/j.frl.2011.01.001

LUCEY, B. M., \& LI, S. (2015). What precious metals act as safe havens, and when? Some US evidence. Applied Economics Letters, 22(1), 35-45. https://doi.org/10.1080/13504851.2014.920471

MENSI, W., SENSOY, A., VO, X. V., \& KANG, S. H. (2020). Impact of COVID-19 outbreak on asymmetric multifractality of gold and oil prices. Resources Policy, 69(May), 101829. https://doi.org/10.1016/j.resourpol.2020.101829

NELSON, D. B. (1991). Conditional Heteroskedasticity in Asset Returns : A New Approach. Econometrica, 59(2), 347-370.

OTERO, L. A., \& REBOREDO, J. C. (2018). The performance of precious-metal mutual funds: Does uncertainty matter? International Review of Financial Analysis, 57, 13-22. https://doi.org/10.1016/j.irfa.2018.02.003

QIAN, Y., RALESCU, D. A., \& ZHANG, B. (2019). The analysis of factors affecting global $\begin{array}{llll}\text { gold price. Resources } & \text { Policy, }\end{array}$ https://doi.org/10.1016/j.resourpol.2019.101478

QIN, M., SU, C. W., QI, X. Z., \& HAO, L. N. (2020). Should gold be stored in chaotic eras? Economic Research-Ekonomska Istrazivanja , 33(1), 224-242. https://doi.org/10.1080/1331677X.2019.1661789

SARI, R., HAMMOUDEH, S., \& SOYTAS, U. (2010). Dynamics of oil price, precious metal prices, and exchange rate. Energy Economics, 32(2), 351-362. https://doi.org/10.1016/j.eneco.2009.08.010

SCHWERT, G. W. (1990). Stock market volatility. Financial Analysts Journal, 46(3), 23-34. 